[Chem. Pharm. Bull.

34(10)4394-4399(1986).

\title{
Porcine Pancreatic Prokallikrein. IV. N-Terminal Amino Acid Sequences of Prokallikrein B and the Kallikrein Generated from It by the Action of Trypsin
}

\author{
Kazuyuki Kizuki, * Hiroshi Murakami, Masaharu Hiratsuka, \\ Masafumi Kamada and Hiroshi Moriya \\ Department of Biochemistry, Faculty of Pharmaceutical Sciences, \\ Science University of Tokyo, 12, Ichigaya-Funakawara-machi, \\ Shinjuku-ku, Tokyo 162, Japan
}

(Received May 26, 1986)

\begin{abstract}
Porcine pancreatic prokallikreins A and B were separately highly purified by water extraction in the presence of various protease inhibitors, ammonium sulfate salting-out fractionation, anionexchange chromatography, immunoaffinity chromatography on an anti-porcine pancreatic kallikrein B antibody immobilized Sepharose 4B column and gel filtration on Sephacryl S-200. The specific activities of the final prokallikreins $A$ and $B$ preparations were 75.0 and $79.4 \mathrm{EU} / A_{280}$ (when assayed after activation with trypsin), respectively, and the prokallikrein $B$ preparation showed a single band on the sodium dodecyl sulfate-polyacrylamide gel electrophoresis.

The N-terminal amino acid sequence of prokallikrein B was H-Ala-Pro-Pro- and that of kallikrein B", which is the kallikrein generated from prokallikrein B by the action of trypsin, was $\mathrm{H}-$ Ile-Ile-Gly-Gly-. The latter sequence agreed with that of the A-chain of kallikrein B, which is the kallikrein obtained from the autolyzed pancreas.
\end{abstract}

Keywords_-_kallikrein-kinin system; porcine pancreatic kallikrein; prokallikrein; tissue kallikrein; amino acid sequence; trypsin

Kallikrein in porcine pancreas is considered to exist mainly as its inactive form "prokallikrein" and to be activated to its functional form "kallikrein" by the action(s) of protease(s) in the pancreas or body fluid. However, several different forms of kallikrein generated from prokallikrein have been reported, i.e., single-polypeptide-chain kallikrein $(\alpha-$ kallikrein), two-chain kallikrein ( $\beta$-kallikrein) and three-chain kallikrein ( $\gamma$-kallikrein) ${ }^{1,2)}$ In order to elucidate the physiological and/or pathological significance of tissue kallikrein in the body, investigations to identify the enzyme(s) involved in the activation of prokallikrein in the body and to clarify the mechanism of activation of prokallikrein are very important.

The present paper deals with the isolation of porcine pancreatic prokallikreins A and B and the N-terminal amino acid sequence analyses of prokallikrein B and kallikrein $\mathrm{B}^{\prime \prime}$ generated from it by the action of trypsin.

\section{Materials and Methods}

Materials - - Fresh porcine pancreas was obtained from a slaughterhouse and stored at $-25^{\circ} \mathrm{C}$ until required. The authentic phenylthiohydantoin (PTH)-amino acids were purchased from Pierce Chemical Co. (Rockford, IL., U.S.A.). Trypsin from porcine pancreas (type IX) and trypsin inhibitor from soybean (type I-S) (SBTI) from Sigma Chemical Co. (St. Louis, Mo., U.S.A.) were used for activation and the assay of prokallikrein. Kallikrein B" (105.1 $\mathrm{EU}\left(A_{280}\right)$ purified previously ${ }^{2)}$ was also used. Other reagents used were of guaranteed grade or the same as those mentioned in our previous papers. ${ }^{3,4)}$

Esterolytic Activity Assay_-Esterolytic activity towards $N^{\alpha}$-benzoyl-L-arginine ethyl ester (BzArgOEt) was measured photometrically as a kallikrein assay, and the activity was expressed in esterase units (EU). One EU is the 
amount of enzyme that can hydrolyze $1 \mu \mathrm{mol}$ of BzArgOEt per min at $25^{\circ} \mathrm{C}$ and $\mathrm{pH} 8.0$. The amount of prokallikrein was determined in the same way as that mentioned in our previous paper, namely the amount of prokallikrein was estimated and expressed as EU after activation with trypsin. ${ }^{3)}$

Preparation of Anti-Porcine Pancreatic Kallikrein Antibody Immobilized Sepharose 4B Column-_-Kallikrein B was purified from autolyzed porcine pancreas ${ }^{5}$ and was used for the preparation of anti-porcine pancreatic kallikrein $\mathrm{B}$ rabbit serum. The anti-porcine pancreatic kallikrein $\mathrm{B}$ rabbit serum obtained by the same procedures as mentioned in our previous paper ${ }^{4}$ (total $4370 A_{280}$ ) was diluted 2-fold and ammonium sulfate was added to it. The precipitate between $0-40 \%$ saturation was collected by centrifugation $\left(7000 \mathrm{~g}, 30 \mathrm{~min}\right.$ at $\left.4{ }^{\circ} \mathrm{C}\right)$. The precipitate was dissolved in distilled water and dialyzed against $0.0175 \mathrm{M}$ phosphate buffer, $\mathrm{pH}$ 8.0. Then, the dialysate was applied to a diethyl aminoethyl (DEAE)-cellulose column $(2.2 \times 25.0 \mathrm{~cm})$ equilibrated with the same buffer and the non-adsorbed fraction (total $1064 A_{280}$ ) was pooled and used for preparation of anti-porcine pancreatic kallikrein antibody-immobilized Sepharose $4 \mathrm{~B}$ according to the method of Cuatrecasas. ${ }^{6)}$ The amount of immobilized protein was $2.54 \mathrm{mg} / \mathrm{ml}$ of Sepharose 4B gel.

Sodium Dodecyl Sulfate (SDS)-Polyacrylamide Gel Electrophoresis_- This was carried out as described by Laemmli. ${ }^{7)}$ Samples were treated with or without $5 \%$ (v/v) 2-mercaptoethanol (2-ME) in $0.0625 \mathrm{M}$ Tris- $\mathrm{HCl}$ buffer, $\mathrm{pH} 6.8$, containing both $2 \%(\mathrm{w} / \mathrm{v}) \mathrm{SDS}$ and $6 \%(\mathrm{v} / \mathrm{v})$ glycerol for $3 \mathrm{~min}$ at $100{ }^{\circ} \mathrm{C}$. After being fixed with $12.5 \%(\mathrm{w} / \mathrm{v})$ trichloroacetic acid, proteins were stained with Coomassie brilliant blue R-250 dissolved in $\mathrm{MeOH}-\mathrm{AcOH}-\mathrm{H}_{2} \mathrm{O}$ $(9: 2: 9, \mathrm{v} / \mathrm{v})$.

Analysis of N-Terminal Amino Acid Sequence- The N-terminal amino acid sequences of prokallikrein B and kallikrein $\mathbf{B}^{\prime \prime}$ were identified by a combination of manual Edman degradation and high performance liquid chromatography (HPLC) on a Shodex ODSpak F-511A column $(4.6 \times 250 \mathrm{~mm}$, Showa Denko Co., Tokyo). The lyophilized prokallikrein B $\left(0.262 A_{280}\right.$ eq. $)$ and kallikrein $\mathrm{B}^{\prime \prime}\left(0.340 A_{280}\right.$ eq. $)$ were used. The manual Edman degradations were performed by the three-stage method of Edman as described by Sauer et al. ${ }^{8)}$ A $20 \mu$ l aliquot of the

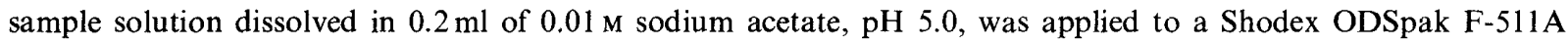
column and developed with the same sodium acetate solution containing $32.5 \%$ acetonitrile at a flow rate of $1 \mathrm{ml}$ per min at $70^{\circ} \mathrm{C}$. The retention times of the PTH-amino acids were automatically recorded on an autorecorder by measuring the absorbance at $269 \mathrm{~nm}$.

\section{Results}

\section{Purification of Prokallikreins A and B}

All of the following procedures were carried out at $0-2{ }^{\circ} \mathrm{C}$. Porcine pancreas $(500 \mathrm{~g})$ was minced with a meat grinder and 1.51 of ammonium sulfate solution (electric conductivity $5 \mathrm{~m} \mho / \mathrm{cm}$ ), $\mathrm{pH} 6.0$, containing benzamidine (final concentration $10 \mathrm{~mm}$ ), N-ethylmaleimide $(10 \mathrm{~mm})$, ethylenediaminetetraacetic acid disodium salt (EDTA $2 \mathrm{Na})(10 \mathrm{~mm})$ and SBTI $(1.5 \mathrm{~g})$ was added to it. The $\mathrm{pH}$ was adjusted to 4.8 with $1 \mathrm{~N} \mathrm{HCl}$, and the mixture was stirred for $3 \mathrm{~h}$. Then, it was centrifuged for $30 \mathrm{~min}$ at $7000 \mathrm{rpm}$ and the supernatant was obtained. Solid ammonium sulfate was added to this supernatant and the precipitate formed between 33 and $80 \%$ saturation was collected. The precipitate was dissolved in $\mathrm{H}_{2} \mathrm{O}(300 \mathrm{ml})$ containing $6 \mathrm{mg}$ of SBTI and the $\mathrm{pH}$ was adjusted to 6.0 with diluted ammonia solution. The solution was dialyzed for $10 \mathrm{~h}$ against $\mathrm{H}_{2} \mathrm{O}$. After centrifugation $(7000 \mathrm{rpm}, 30 \mathrm{~min})$, the clear supernatant was obtained. This solution contained $700 \mathrm{EU}$ of prokallikrein. The electric conductivity and the $\mathrm{pH}$ of the supernatant were adjusted to $5.0 \mathrm{~m} \mho / \mathrm{cm}$ and 6.0 , respectively, and the solution was applied to a carboxymethyl $(\mathrm{CM})$-cellulose column $(4.5 \times 30 \mathrm{~cm})$ equilibrated with $5.0 \mathrm{~m} \sigma / \mathrm{cm}$ of ammonium acetate, $\mathrm{pH} 6.0$. Non-adsorbed substances were then directly applied to a DEAE-Sepharose CL-6B column and the substances adsorbed on the column were eluted (Fig. 1). As shown in Fig. 1, prokallikrein A (fraction No. 90-118) and prokallikrein B (fraction No. 60-89) were eluted before the active kallikrein. Prokallikreins A and B fractions were separately pooled and then immunoaffinity chromatographies were carried out. As shown in Fig. 2, prokallik reins were ad sorbed on the column and eluted with diluted $\mathrm{HCl}(\mathrm{pH}$ 2.8). The pooled prokallikreins $\mathrm{A}$ and $\mathrm{B}$ solutions were concentrated and separately gel-filtered on a Sephacryl S-200 column. Prokallikreins A and B were each eluted as a single peak. The separately pooled prokallikreins $\mathrm{A}$ and $\mathrm{B}$ fractions obtained after the gel filtrations had specific activities of 75.0 and $79.4 \mathrm{EU} / A_{280}$, respectively. However, these prokallikreins $\mathrm{A}$ and $\mathrm{B}$ preparations contained 10 and $36.3 \%$ of active form, 


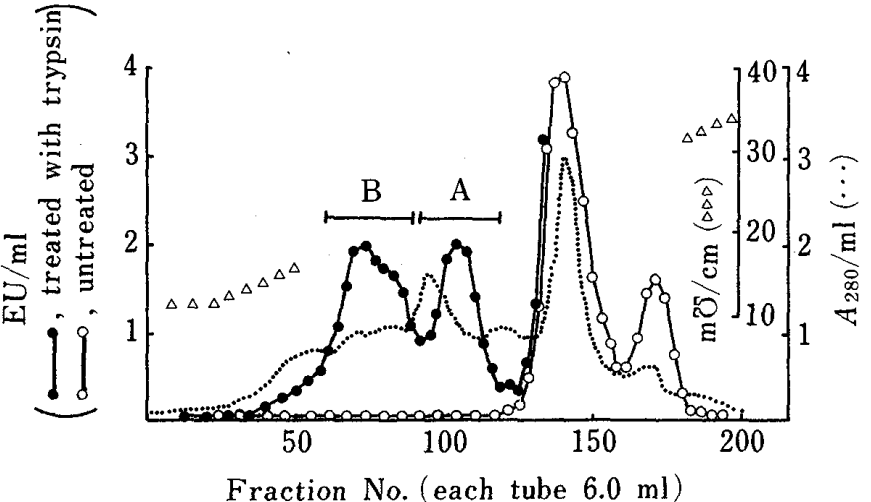

Fig. 1. Elution Profiles of Porcine Pancreatic Prokallikreins A and B from a DEAE-Sepharose CL-6B Column

Non-adsorbed fractions from a CM-cellulose column were directly applied to a DEAE-Sepharose CL$6 \mathrm{~B}$ column $(3.0 \times 25 \mathrm{~cm})$ equilibrated with $5.0 \mathrm{m \mho} / \mathrm{cm}$ ammonium acetate, $\mathrm{pH}$ 6.0. The column was washed with $500 \mathrm{ml}$ of the same solution and further with $10.0 \mathrm{~m} \mho / \mathrm{cm}$ ammonium acetate, $\mathrm{pH} 6.0$, until the $\mathrm{ab}-$ sorbance at $280 \mathrm{~nm}$ of the eluate was less than 0.1 . Then, linear gradient elution with 10.0 to $35.0 \mathrm{~m} \sigma / \mathrm{cm}$ ammonium acetate, $\mathrm{pH} 6.0$ (total $1600 \mathrm{ml}$ ) was carried out. $\longrightarrow$ in the figure shows the fractions pooled for prokallikreins A and B.

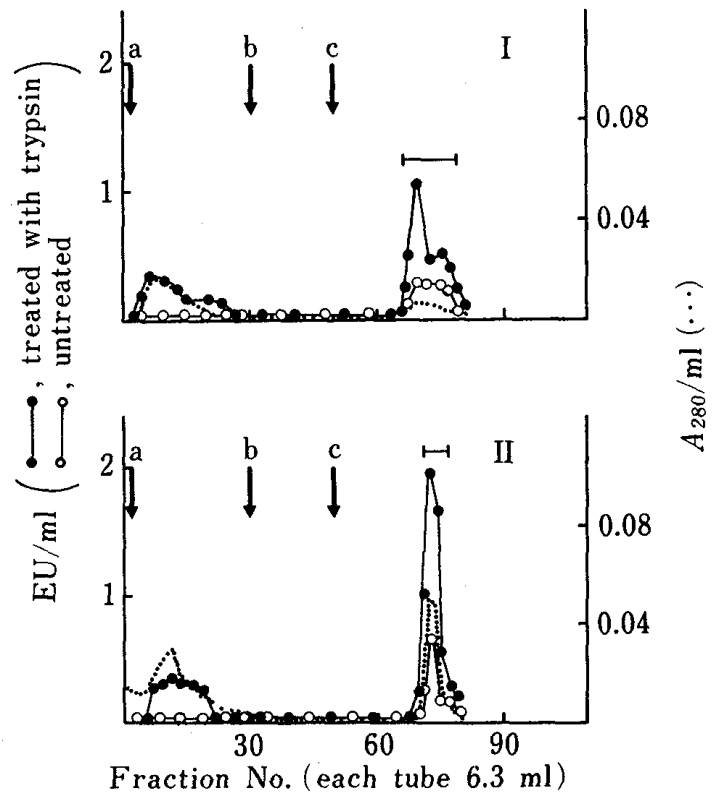

Fig. 2. Immunoaffinity Chromatographies of Porcine Pancreatic Prokallikreins A (I) and B (II)

Porcine pancreatic prokallikrein A fractions pooled in Fig. 1 were dialyzed against $10.0 \mathrm{~m} \mho / \mathrm{cm}$ ammonium acetate, $\mathrm{pH} 6.0$, and concentrated to $12.3 \mathrm{ml}$. The concentrate was again dialyzed against $0.01 \mathrm{M}$ phosphate buffer, $\mathrm{pH} 7.4$, containing $0.2 \mathrm{M} \mathrm{NaCl}$. A half of the dialysate was applied to an anti-porcine pancreatic kallikrein B antibody-immobilized Sepharose $4 \mathrm{~B}$ column $(2.6 \times 10.0 \mathrm{~cm})$, which was allowed to stand for $10 \mathrm{~h}$ at $4{ }^{\circ} \mathrm{C}$. The column was washed with about $200 \mathrm{ml}$ of the same buffer. Then, the column was washed with $0.01 \mathrm{M}$ phosphate buffer, $\mathrm{pH} 7.4$, containing both $1.0 \mathrm{M} \mathrm{NaCl}$ and $0.1 \%$ Triton X-100 (a), $0.001 \mathrm{M}$ phosphate buffer, $\mathrm{pH} 7.4$ (b) and diluted $\mathrm{HCl}, \mathrm{pH} 2.8$ (c)

Prokallikrein B fractions pooled in Fig. 1 were also concentrated to $25.0 \mathrm{ml}$ and the same procedures as mentioned above were carried out.

TABLE I. Summary of the Purification of Porcine Pancreatic Prokallikreins A and B

\begin{tabular}{|c|c|c|c|c|c|c|}
\hline Purification step & & $\begin{array}{l}\text { Protein } \\
\left(A_{280}\right)\end{array}$ & $\begin{array}{l}\text { Prokallikrein } \\
\qquad(\mathrm{EU})^{a)}\end{array}$ & $\begin{array}{l}\text { Recovery } \\
(\%)\end{array}$ & $\begin{array}{c}\mathrm{S} . \mathrm{A} \cdot{ }^{d)} \\
\left(\mathrm{EU} / A_{280}\right)\end{array}$ & P.F. $^{e)}$ \\
\hline $\begin{array}{l}\text { Dialysate of } 33-80 \% \\
\left(\mathrm{NH}_{4}\right)_{2} \mathrm{SO}_{4} \text { precipitate }\end{array}$ & & 10271 & $700^{b)}$ & 100 & 0.068 & 1 \\
\hline DEAE-Sepharose CL-6B & A) & 174 & $195(2.6)^{c)}$ & 27.9 & 1.12 & 16 \\
\hline chromatography & B) & 168 & $263(0.0)$ & 37.6 & 1.57 & 23 \\
\hline Immunoaffinity & A) & 0.10 & $3.7(13.5)$ & 0.5 & 37.0 & 544 \\
\hline chromatography & B) & 1.14 & $55.9(24.5)$ & 8.0 & 49.0 & 721 \\
\hline Sephacryl S-200 & A) & 0.04 & $3.0(10.0)$ & 0.4 & 75.0 & 1103 \\
\hline gel filtration & B) & 0.17 & $13.5(36.3)$ & 1.9 & 79.4 & 1168 \\
\hline
\end{tabular}

a) Assayed after treatment with trypsin. b) The total kallikrein (after treatment with trypsin) in the dialysate of $33-80 \%$ $\left(\mathrm{NH}_{4}\right)_{2} \mathrm{SO}_{4}$ precipitate was $2509 \mathrm{EU}$ and the amount of active form of kallikrein (before treatment with trypsin) was $1809 \mathrm{EU}$. Thus, the amount of prokallikrein in this dialysate was $700 \mathrm{EU}$. Active form of kallikrein in this dialysate was separated from prokallikrein by the next anion-exchange chromatography. c) Contents of the active form of kallikrein (EU, untreated/EU, treated with trypsin X 100). d) Specific activity. e) Purification factor.

respectively, which were spontaneously generated from prokallikreins during these purification procedures because we had pooled prokallikrein fractions which contained almost no active kallikrein from the DEAE-Sepharose $\mathrm{CL}=6 \mathrm{~B}$ chromatography (Fig. 1). Table I summarizes the purification of prokallikreins $\mathrm{A}$ and $\mathrm{B}$ mentioned above. 


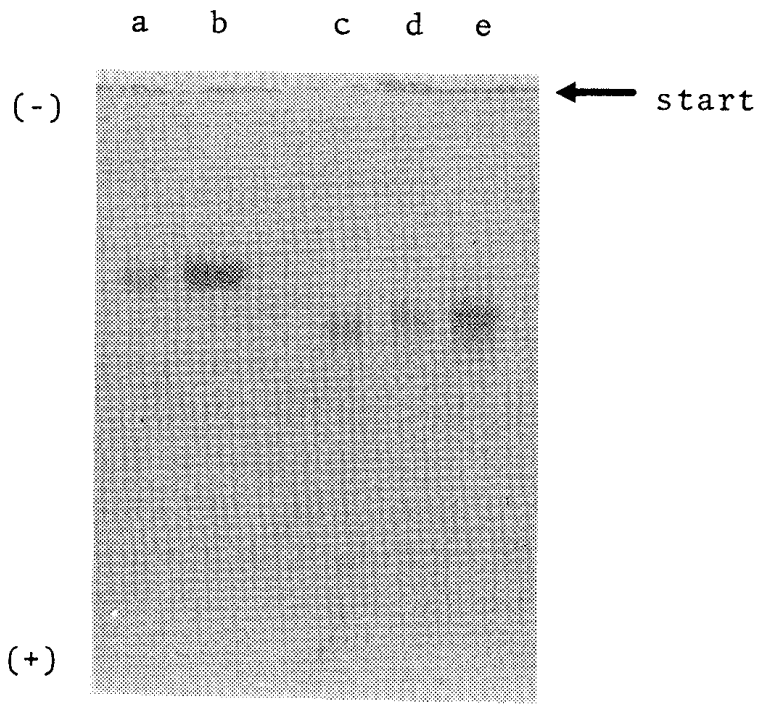

Fig. 3. SDS-Polyacrylamide Gel Electrophoresis of Prokallikrein B and Kallikrein B before and after Reduction with 2-ME

a. Prokallikrein B (0.108 EU), after the reduction.

b. Prokallikrein B $(0.320 \mathrm{EU})$, after the reduction.

c. Kallikrein B $(0.220 \mathrm{EU})$, before the reduction.

d. Prokallikrein $B(0.108 \mathrm{EU})$, before the reduction.

e. Prokallikrein B (0.324 EU), before the reduction.

TABle II. Manual Edman Degradation of Prokallikrein B and Kallikrein B"

\begin{tabular}{|c|c|c|c|c|}
\hline \multirow{2}{*}{ Cycle } & \multicolumn{2}{|c|}{ Prokallikrein B } & \multicolumn{2}{|c|}{ Kallikrein $\mathbf{B}^{\prime \prime}$} \\
\hline & Residue & Yield $^{a)}$ & Residue & Yield $^{a)}$ \\
\hline \multirow{2}{*}{1} & Ala & 873 & \multirow[b]{2}{*}{ Ile } & \multirow[b]{2}{*}{4700} \\
\hline & Ile & 496 & & \\
\hline \multirow{2}{*}{2} & Pro & 192 & \multirow[b]{2}{*}{ Ile } & \multirow[b]{2}{*}{2650} \\
\hline & Ile & 146 & & \\
\hline 3 & Pro & 60 & Gly & 928 \\
\hline 4 & & & Gly & 395 \\
\hline
\end{tabular}

a) pmol.

1. rat pancreatic kallikrein ${ }^{10)}$

2. human pancreatic kallikrein ${ }^{11}$

3. human urinary kallikrein ${ }^{12)}$

4. human urinary kallikrein ${ }^{13)}$

5. mouse submaxillary gland kallikrein ${ }^{14)}$

6. porcine pancreatic kallikrein ${ }^{9)}$
$-28$

Met-Pro-Val-Thr-Met-Trp-Phe-Leu-Ile-Leu-Phe-Leu-Ala-Leu-Ser-LeuMet-Trp-Phe-Leu-Val-Leu-Cys-Leu-Ala-Leu-Ser-Leu-

Met-Trp-Phe-Leu-Ile-Leu-Phe-Leu-Ala-Leu-Ser-Leu-

$$
-10 \downarrow-1 \downarrow+1
$$

1. Gly-Arg-Asn-Asp-Ala-Ala-Pro-Pro-Val-Gln-Ser-Arg-Val-Val-Gly-Gly-Tyr-Asn-Cys-Glu-Met-Asn--

2. Gly-Gly-Thr-Gly-Ala-Ala-Pro-Pro- Ile-Gln-Ser-Arg-Ile-Val-Gly-Gly-Trp-Glu-Cys-Glu-Gln-His---_

3.

4. Ala-Pro-Pro- Ile-Gln-Ser-Arg-Ile-Val-Gly-Gly-Trp-Glu-( )-Glu-Gln-His--.--

Gly-Gly- Ile -Asp-Ala-Ala-Pro-Pro-Val-Gln-Ser-Arg- Ile-Val-Gly-Gly-Phe-Lys-Cys-Glu-Lys-Asn----

$$
\text { Ala-Pro-Pro-( )- Ile-Ile-Gly-Gly-Arg-Glu-Cys-Glu-Lys-Asn---- }
$$

Fig. 4. Amino Acid Sequences Near the Pro-Region of Kallikreins from Various Origins

The N-terminal amino acid sequence of porcine pancreatic prokallikrein, H-Ala-ProPro-, obtained in the present study was added to the sequence of A-chain of porcine pancreatic kallikrein reported by Fiedler et al. ${ }^{9)}$ The arrows show the predicted cleavage points for pre-pro-porcine pancreatic kallikrein. 
Figure 3 shows the results of SDS-polyacrylamide gel electrophoresis of prokallikrein B before and after reduction with 2-ME. Before the reduction with 2-ME, prokallikrein $\mathrm{B}$ showed a broad band (Fig. 3d and e) which migrated slightly more slowly than kallikrein B (Fig. 3c). Prokallikrein B also showed a single band after the reduction with 2-ME (Fig. 3a and $b$ ).

\section{N-Terminal Amino Acid Sequence}

When kallikrein B" was subjected to manual Edman degradation, PTH-Ile, -Ile, -Gly and-Gly were identified at the first 4 cycles as PTH-amino acids (no contaminating PTH-amino acid could be observed at each cycle) (Table II). Thus, the $\mathrm{N}$-terminal amino acid sequence of kallikrein B" was identified as H-Ile-Ile-Gly-Gly-. On the other hand, when prokallikrein B was subjected to the manual Edman degradations, PTH-Ala and -Ile were identified at the 1st cycle of degradation. PTH-Pro and-Ile were identified at the 2nd cycle, and PTH-Pro was identified at the 3rd cycle. Thus, the N-terminal amino acid sequence of prokallikrein B might be H-Ala-Pro-Pro-(see Discussion).

\section{Discussion}

It is well known that porcine pancreatic kallikrein obtained from autolyzed pancreas is usually. separated into two main components, i.e., kallikreins A and B, by anion-exchange chromatographies. These kallikreins are $\beta$-kallikrein. On the other hand, kallikreins $\mathrm{A}^{\prime \prime}$ and $\mathrm{B}^{\prime \prime}$ generated from prokallikreins $\mathrm{A}$ and $\mathrm{B}$ by the action of trypsin are $\alpha$-kallikrein. Besides these kallikreins, kallikreins $\mathrm{A}^{\prime}$ and $\mathrm{B}^{\prime}$, which are kallikreins spontaneously generated during the purification of prokallikreins, were also reported. ${ }^{9)}$ These kallikreins are also $\alpha$-kallikrein. The specific activities of the purified kallikreins mentioned above are $90-110 \mathrm{EU} / A_{280}{ }^{2}{ }^{2} \mathrm{Our}$ final prokallikreins A and B preparations had specific activities of 75.0 and $79.4 \mathrm{EU} / A_{280}$, respectively, when assayed after activation with trypsin. Although these values were slightly lower than those mentioned above, the high purities of these preparations were confirmed by the SDS-polyacrylamide gel electrophoresis. However, a broad protein band was observed, especially when a high dose of prokallikrein B was subjected to electrophoresis (Fig. 3e). Our present final prokallikrein B preparation contained about $36 \%$ of active form (Table I). Therefore, the broad band can be explained by the coexisting active form kallikrein, as judged from the migration length of kallikrein B (Fig. 3c) and also from the results obtained in our detailed comparison of various kallikreins generated from prokallikreins. ${ }^{2)}$

The N-terminal amino acid sequence of kallikrein $\mathrm{B}^{\prime \prime}$ was determined to be $\mathrm{H}-\mathrm{Ile}-\mathrm{Ile}$ Gly-Gly-. This sequence is identical with that of A-chain of kallikrein B. ${ }^{9)}$ On the other hand, we observed (Ala, Ile) and (Pro, Ile) on the 1st and 2nd cycles of Edman degradation, respectively. Figure 4 summarizes the already known near pro-region structures of various kallikreins which were obtained from analyses of their messenger ribonucleic acid and complementary deoxyribonucleic acid or direct polypeptide chain analyses. Judging from these sequences and our present results, the $\mathrm{N}$-terminal amino acid sequence of prokallikrein $\mathrm{B}$ might be $\mathrm{H}-\mathrm{Ala}-\mathrm{Pro}-\mathrm{Pro}-$; the Ile observed at the 1 st and 2 nd cycles was considered to be derived from active kallikrein coexisting in the prokallikrein B preparation. We could not detect the amino acid sequence of prokallikrein $B$ after the 3 rd cycle since the amount of prokallikrein B preparation was insufficient for the manual Edman degradation. However, as shown in Fig. 4, the pro-region amino acid sequences of kallikreins from various origins are extremely similar to each other. Thus, the present study indicated that a peptide consisting of 7 amino acids would be released when porcine pancreatic prokallikrein is activated, although it remains to be determined whether or not trypsin is the true physiological activator of prokallikrein in the body. 
Acknowledgements We would like to thank Dr. Tadashi Yasuhara, Institute for Medical and Dental Engineering, Tokyo Medical and Dental University, and Prof. Terumi Nakajima, Faculty of Pharmaceutical Sciences, University of Tokyo, for valuable advice and discussions on the manual Edman degradation. This work was supported in part by Grants-in-Aids for Scientific Research from the Ministry of Education, Science and Culture of Japan, from Toray Science Foundation and from the Ryoichi Naito Foundation for Medical Research.

\section{References}

1) F. Fiedler and C. Hirschauer, Hoppe-Seyler's Z. Physiol. Chem., 362, 1209 (1981).

2) K. Kizuki, H. Takiguchi, M. Kamada, M. Ikekita and H. Moriya, Chem. Pharm. Bull., 32, 3662 (1984).

3) K. Kizuki, M. Ikekita, Y. Shimamoto and H. Moriya, Chem. Pharm. Bull., 30, 2561 (1982).

4) K. Kizuki, M. Kamada, M. Ikekita and H. Moriya, Chem. Pharm. Bull., 30, 3354 (1982).

5) M. Ikekita, H. Moriya, S. Ozawa and K. Kizuki, Chem. Pharm. Bull., 29, 545 (1981).

6) P. Cuatrecasas, J. Biol. Chem., 245, 3059 (1970).

7) U. K. Laemmli, Nature (London), 227, 680 (1970).

8) R. T. Sauer, H. D. Niall, M. L. Hogan, H. T. Keutmann, J. L. H. O'Riordan and J. T. Potts, Jr., Biochemistry, 13, 1994 (1974).

9) F. Fiedler, E. Fink, H. Tschesche and H. Fritz, Methods in Enzymology, 80, 493 (1981).

10) G. H. Swift, J. C. Dagorn, P. L. Ashley, S. W. Cummings and R. J. MacDonald, Proc. Natl. Acad. Sci. U.S.A., 79, 7263 (1982).

11) D. Fukushima, N. Kitamura and S. Nakanishi, Biochemistry, 24, 8037 (1985).

12) S. Takahashi, A. Irie, Y. Katayama, K. Ito and Y. Miyake, J. Biochem. (Tokyo), 99, 989 (1986).

13) F. Lottspeich, R. Geiger, A. Henschen and C. Kutzbach, Hoppe-Seyler's Z. Physiol. Chem., 360, 1947 (1979).

14) A. J. Mason, B. A. Evans, D. R. Cox, J. Shine and R. I. Richards, Nature (London), 303, 300 (1983). 